\title{
Human Language, (Its Concept, Features and Functions)
}

\author{
Mohamed Moustafa Ahmed Younes \\ The Egyptian Ministry of Education, Fayoum Directorate of Education, Fayoum, Egypt
}

Email address:

younusmohamed2@gmail.com

\section{To cite this article:}

Mohamed Moustafa Ahmed Younes. Human Language, (Its Concept, Features and Functions). Arabic Language, Literature \& Culture. Vol. 6, No. 1, 2021, pp. 20-25. doi: 10.11648/j.allc.20210601.13

Received: February 24, 2021; Accepted: March 17, 2021; Published: March 26, 2021

\begin{abstract}
The human language possesses features that distinguish it from other non-human languages - if this expression is correct - it determines the humanity of man. Without it society would be without spirit and man and animals would be equal in this respect. Language is a human phenomenon; because only man can place his mental activity in linguistic symbols, and accordingly, creatures other than man cannot acquire any human language in one form or another; because it is not prepared or equipped for that, it does not have the mental capacity to acquire the language, and it does not have sufficient intelligence to develop linguistic symbols through which they can formulate a language suitable for understanding, with its own connotations, and its distinctive phonological manifestations. If these animals are unable to place their mental activity in linguistic symbols, then the basis of human mental activity is the use of linguistic symbols, as he has awareness of the signs that he uses as means to achieve his purposes, and he also has a conscious intention when using them, and then he chooses from among them what he deems appropriate. For the position that it expresses. As for the animal, it does not have this perception, or this intention, because the person possesses an innate apparatus called the linguistic faculty (the linguistic ability) or what is called (the latent competence) in the mind, which makes the person ready to acquire any language that lives in its surroundings without effort. In addition to the fact that a person is able to pass on this language that he acquired to the generations that follow without intentionally or preparing, so language is acquired and inherited without effort or planning. Although researchers on the issue of the genesis of human language have not reached - with certainty - to determine how it arose, and in what form it arose, no one denies the importance of language for all of humanity; because research in language is a search in the human being himself. For this reason, God Almighty has distinguished man with language, language has distinguished him from other animals, and those who think that language is merely a means of expressing ideas, or a means of communication between man and those around him are mistaken; because language is often in response to man's innate tendency to prove His social presence.
\end{abstract}

Keywords: Human Language, Features of Language, Concept of Language, Function of Language, Linguistic System

\section{Introduction}

Those who think that language is just a means of expressing ideas or a means of communication between a person and those around him are mistaken. "Those who say that language is a tool of expression and communication overlook the social function of language... Language is not, in any case, a tool of expression and communication. It may be in many cases a response. Because of man's innate tendency to establish his social existence" (P. 146) [13], even a child who makes imaginary companions for himself (P. 19) [4], talks to them and brings out his inner self, when he does not find someone to accompany him in his play, he is driven
By his instinct as a human being to the social connection between him and those around him, the instinct of social interaction among the child leads him to create an imaginary society when he is unable to exist in a real society for a modern moment with himself. Consequently, Chomsky described the interpretations of those who limited the function of language to being a means of communication between man and himself or man and others, or as a means for the expression of thought and the transmission of information. He described their interpretations as - all of them - empty and vague, and such interpretations will remain metaphysical (P. 40) [4], "Language (in Chomsky) is used to convey information, but it also serves many other purposes. It establishes bonds between people, to express or clarify 
thought, to practice, to generate mental activity, to achieve understanding, and so on." (P. 204 - 205) [4]. Therefore, God Almighty has enabled a person to acquire the language quickly, and in a record time, as he does not exceed four years of age so that he can encompass aspects of the language and create new sentences that he has not heard like before, and in his ability to understand it without effort, even if it is determined for him that Is isolated from human society, he would have been able to acquire language quickly if he lived in a society that acquired language, provided that he did not exceed a certain age after which it would be difficult for him to acquire any language whatsoever.

\section{The Concept of Human Language}

(A) The concept of language at the ancients

In their definition of language, the ancients focused on the following aspects:

1. Language is a voice of the people's humility, with the aim of understanding and communication, which differs in different nations, and has been developed to achieve their goals and express their thoughts and feelings.

2. Language consists of expressions designed to express meanings.

3. Language is a social phenomenon that has psychological aspects that affect the individual and the group.

4. Language is a linguistic property with which a person becomes accustomed and acquired from society until it becomes his property with him.

5. Language is a voluntary action intended by the speaker, and this is what distinguishes man from other animals (P. 107-113, 118, 119) [4].

(B) The concept of language at modern Linguists:

(The concept of language for the ancients does not differ from that of Modern Linguists ones, except in simple aspects) We glimpse this convergence in the following concepts:

1. Language is a picture of the lives of its owners, which elevates their sophistication and retards their backwardness P. 7) [12].

2. Language is a human phenomenon; because only the human being puts his mental activity in linguistic symbols (P. 85) [14].

3. Language is idiomatic signs that can be used to convey idiomatic connotations (P. 171) [10].

4. Language is a system of acquired spoken symbols used by a certain group of people in order to communicate and achieve cooperation among them (P. 150) [13].

5. Language is a group of voluntary human voices, and therefore our dealings with the term language do not include those sounds that animals, birds and insects make, as well as those emotional voices that children make in their first months (P. 9) [5].

\section{Features of Human Language}

The human language has features that distinguish it from other non-human languages - if this expression is correct - it defines the humanity of mankind and without it, society would have been without a soul, and the equality of man and animals in this respect. For this reason, God Almighty distinguished man by language, and language distinguished him from other animals. This is because God Almighty has given man a measure of intelligence that enables him to "translate sounds, interpret them, and then imitate them." In the end, all this led to the formation of his language that has rules and principles" (P. 12) [1]. This is impossible to facilitate for animals, no matter how sophisticated they are. She "did not endow with sufficient mental ability or an innate willingness to have (from her voices) her language" (P. 12) [1]. Likewise, God Almighty has distinguished man with capabilities that are not present in animals, for he - that is, humans - is distinguished from them by "a group of brain centers that oversee the various aspects of language... It has been proven that these centers have no equivalent in the brain of any other animal species, even the factions. The supreme apes themselves" (P. 28) [17]. This is because it is not prepared biologically and organically to perform the task of acquisition, no matter how much she lives in a human environment, and no matter how much she is trained, she cannot acquire a human language in any way.

If some great apes and parrots are able to perform some actions that indicate a measure of intelligence, or imitate some of the words that they have trained or heard, then this cannot be evidence of their ability to acquire language.

In sum, creatures other than humans cannot acquire any human language in one form or another. Because it is not prepared or equipped for that, it does not have the mental capacity to acquire the language, and it does not have sufficient intelligence to develop linguistic symbols through which they can formulate a language suitable for understanding, with its own connotations, and its distinctive phonological manifestations.

There is a false claim that man at the beginning of his creation was a very sophisticated type of great ape, but that the nature of development changed in the centers of his brain in a way that made him later make a language that he speaks instead of the sign language that he used to deal with the sons of his race for a very long period of time. After he developed the sign systems that he used to deal with according to the stages of development that he went through until he finally reached the word (P. 47) [16].

The invalidity of this claim is clear. Because it contradicts our beliefs on the one hand, and the nature of human upbringing on the other hand, as how can this person - whom God Almighty has honored and favored over many of his creation - be among the sects of monkeys ?! And how can a person remain for a long period of time dealing with signs until the year of evolution required that it separate him from his gender and his cousins from the great apes with some development in his body and brain that made him reach this moderate form, and to make a language to replace him with the sign language that he was accustomed to, And facilitate the process of communication between him and the people of 
his sex, and then connect with it to the most sophisticated aspects of linguistic development. It is absolutely inconceivable that the human being at the beginning of his creation in the form that they claimed, lacked humanity, and the word, until nature bestowed upon him the best of creation, which gave him language and uniqueness. God Almighty created man in the way he is now, and gave him the ability to acquire language and deal with it, and then man developed it after that according to the known System of linguistic development.

Among the features of human language:

First: It is an innovative language characterized by infinity:

This means that a person is able to produce an endless number of sentences and expressions that he has never heard before, and is able to comprehend so many sentences and expressions, although he has not degraded their meaning before. This feature is one of the most important features of our human language, so a comparison between the language of a society, whatever this language is, and the language of an animal or bird shows us that bird and animal languages consist of text-specific and specific sound systems, which the animal or bird cannot produce or understand other than. $\mathrm{He}$ can change it or improvise without it.

While human languages are distinguished by the fact that they produce an infinite number of textual sequences, despite their limitations, the sounds, morphological forms, lexical units (expressions) and grammatical rules can be limited, but the relationships existing between them qualify the language practitioner to produce endless pronunciations, or limits to their preparation. Consequently, their verbal messages are multiplied, and they respond to these statements and form their cultural context and cultural traditions (P. 28) [7]. This, of course, is one of the most fundamental differences between human language and the different forms of expression in animals and birds.

Second: Dual linguistic representation

The human language is characterized by the presence of more than one level of linguistic representation, as linguistic research confirms that human languages have at least two levels of linguistic representation, the first of which is the latent level, in which the components of the language are located such as sounds, words, and complex arrangement rules, phonological, morphological, syntactic and semantic rules, and the second is the surface level or level. Audible pronouncement, which is the level at which the final product of these complex linguistic processes appears... The latent level of linguistic representation is related to the various mental-linguistic processes that the brain performs, that is, to the subtle, while the surface spoken level is related to the motor activity resulting from or leading to the latent level. That is, by performance (P. 29) [7].

Third: the language therapist:

Its function is to relate the latent level to the surface level (the latent ability and linguistic performance of Chomsky) and explain one to the other (P. 29) [7]. This is what distinguishes the human language from the language of animals or birds - if this expression is correct - which has only one level of linguistic representation. Because the relationship between the linguistic stimulus and the responses or reaction is a direct, unintended relationship in itself, so there is no need for a therapist to be interested in explaining this relationship. Because it is direct, it requires no interpretation or interpretation.

And the language therapist entrusted with explaining the latent capacity of linguistic performance or vice versa does not exist in other creatures, including the higher levels of apes. The reason for this is that it is present in the human brain and is unparalleled among other creatures, no matter how high they are, and it is called: (Wernicke's area), which is the area responsible for understanding both audible speech and written speech. If a person is injured in this area of the brain; the speech therapist lost his ability to interpret, although the patient's ability to speak is not affected, but he is incoherent. This, in turn, confirms the creative capacity of man, as he is able to understand, create and renew, and among the means of creation and renewal he has a linguistic therapist, through which we can also distinguish between human beings and some of them, through which we can differentiate between the cultural level of people, and also determine the level of understanding and misunderstanding situations, words and sentences, and also differentiate between real and metaphor, and we also learn about the situational or linguistic context... etc. This, in turn, varies between people.

Fourth: The possibility of a semantic confusion:

The occurrence of semantic ambiguity is one of the distinguishing features of human language, if it is impossible to occur in animals or birds, because the ways of expression have a single level that does not accept interpretation. As for human language, it is characterized by what is called the verbal common "where the one sign has more than one sign, and it refers to more than one reference... Similarly, the word " "عَيْن in Arabic is used to refer to the spring of water, the eye of the person and the spy, and the same thing... The possibility of a semantic confusion is not limited in any way to the verbal commonality, but extends to the exchange of the language and the like" (P. 29- 30) [7]. And we cannot get rid of this semantic confusion except through the position or the linguistic context.

Fifthly: the human language, a language capable of dual pronouncement (duality):

Language is composed of structures and sentences and it represents the first pronouncement, and these structures and sentences can be divided into smaller components, such as different structures and formulas, which represent the second pronouncement. The various other structures and forms can be divided into phonemic units, and they represent the third pronunciations. Accordingly, this duality of language components, starting from its sentences and ending with its sounds, is a special feature of human language that cannot be accomplished in another communicative organization (P. 17) [2].

Sixth: the human language is characterized by arbitrariness in the relation of words to their meanings, as it is customary: 
When we contemplate an expression of the language, it appears to us that considering it an arbitrary symbol is a clear matter. We could have used another word to express the same thing. The Arabs once called the word "قَّ" to the tool in which they write, and it was possible that they used another word, so there is no necessary relationship between the word and this tool; all there is the random selection of the word. However, language is not only individual units (words), as each unit of the language has a clear and steady relationship with other units, in fact it is used according to an agreement between the speakers. The language - based on this - and as a result of this agreement, it can be said that it is customary... The agreement of the group of Arabic speakers is not limited to the use of expressions as previously mentioned, but rather includes all forms of language (building words or constructing sentences). This agreement is not an explicit or clear act... it is only an agreement in conduct and action ( $\mathrm{P}$. 100, 101) [13]. However, all the words of the language are not customary, for there are a number of words whose voices are evidence of their meaning... Among these words in Arabic are swish, grouse, wheeze, and such as giggle and groan.

Seventh: the human language can be articulated (binary classification):

Linguistic analyzes proved that the linguistic structure - in any language - consists of independent units that can be separated during analysis, such as the separation of phonemes at the phonemic level and morphs at the morphological and structural level. This separation characterizes the human language, excluding all other means of communication (P. 19). [2].

This is also called the term (binary classification), as human languages are distinguished from all symbolic systems in that the linguistic symbol is the only one among the symbols that accepts binary classification within the framework of a particular language.

The linguistic system is based on a list of units that do not carry a meaning in themselves, but they perform the function of differentiating between different meanings, so (الباء) in (بَّلَ) has no meaning in itself, but it performs a functional meaning if it is placed opposite (الواو) in the word (وَلَّد) where It differentiates between two different meanings, and in the word (boy) (الواو) plays the same functional role that the (الباء) plays in the word (بَّلَ).

If we go the systematic way to analyze the phonemic substance of speech, we find ourselves in front of two levels of analysis, the first of which represents the analysis of speech into (morphological units) and the second represents the analysis of speech itself into phonemes (phonemic units) and the morphological units can of course be analyzed into the phonemic units that compose them (P. 95, 96) [15].

But is all human language amenable to articulation or binary classification?

The answer to this question must be negative. A person is able to use non-linguistic symbols that carry special intended or known connotations, such as wearing black for Egyptians to denote sadness, and like traffic lights that express stopping, preparing, or walking (P. 96 - 97) [13]. However, it cannot be subject to the possibility of binary classification or (articulation), as in the linguistic symbols, however it differs completely from the means of communication in the animal as it is separated by the intention of man and his lack of it in the animal. Hence, we cannot call the animal cries of fear as symbols. Because it is not intended in and of itself, moreover, it cannot be divided into syllables, or divided into phonemic symbols. Therefore, the possibility of binary classification (articulation) remains a special feature of human language.

Eighth: the human language is able to transform across time and space:

Man can express with language the past, present and future, and he can also break through the barrier of place, as he was able to break through the barrier of time, and he can as well - convert his thoughts into words. Human language is also capable of penetrating man's imagination and revealing his secrets. It also penetrates future aspirations, revealing their matter and revealing their cover. It is - truly - a great capacity that enables man to transcend the boundaries of time and space, the limits of thought and imagination, and the limits of wishes, so they come out in the form of words. So language is able to convert all this vast amount of dead objects into living spoken or written words.

Ninth: the human language is capable of inheritance:

The human language is an acquired language, which children acquire from adults, generation after generation, with its ability to continuously develop across generations. As for animal expressions, they are instinctive and have not changed for thousands of years. They are fixed behavior in animals that are not subject to development. This is because "human beings are unique in many considerations, and one of these configurations is their abilities to acquire a rich and varied language system" (P. 41) [6]. This makes the person ready to acquire any language he lives in its surroundings without effort. In addition to the fact that a person is able to pass on this language that he acquired to the generations that follow without intentionally or preparing, so language is acquired and inherited without effort or planning.

\section{The Function of Human Language}

The function of the human language is confined to three main foundations, from which secondary functions are branched out, as follows (P. 33-40) [11].

First: the communicative function:

Communication is a rich means in two respects, firstly: the multiplicity of means of communication between humans, and the second: the multiplicity of communication functions. The communicative function: divided into:

(A) Expressive function: in language, a person can express his feelings, his thoughts and perceptions, and he can - as well - express his inner world and the external world, and he can also express his pain and sorrows, express his joys, and express about himself in distress and Prosperity, and in hardship and ease.

(B) The interpretive function: the message - the mediator 
between the sender and the receiver - must go through a mental processing stage, so the speaker who expresses his thoughts, opinions and feelings - in his message that he sends to the listener - only stimulates the listener's thought with this message. Prepare himself to respond to them, here comes the role of the interpretive function of the message where the message turns into ideas, then these ideas - after formulating and reconstructing them - turn into reactions, or into another message where the speaker turns into a listener, and the listener becomes a speaker, and the message rotates between the speaker and the listener. Until the dialogue ends.

If the listener is unable to interpret and understand the message, the interpretive function loses its value, the communication link between the speaker and the listener is cut off, and the message becomes meaningless.

The expressive function alone is not sufficient for the functioning of the communication process, so the interpretive function must be synergistic with it in order for the communication process to be carried out sound without interruption, so that the message has meaning in the mind of the listener.

(C) Personal function: through language, the individual can express his unique visions, feelings and attitudes towards many topics. Through his use of language, he can present his ideas to others, and prove his identity and personal entity ( $P$. 23) [18].

Second: the cognitive function:

The function of language cannot lie behind what it provides us with in terms of ideas and information, or which it suggests to us in terms of feelings... only, but rather excites us - based on that - the desire to think, and to stimulate our perceptions and our imaginations towards other worlds... so that the human being turn from a recipient of ideas, feelings, sensory and moral perceptions. to the creator of new ideas and virgin opinions, as it creates new situations in the human being, and a broader and broader intellectual capacity and a fervent mind, and it also enables the person to develop his thinking, and move it from simple and naive ideas to more complex ideas And depth.

Other sub-functions are branched from the cognitive function, namely:

(A) The educational function: In no case can a child or adult be able to learn except through language, whether written or spoken. Language is the basis and pillar of the educational process in all its aspects, so how does a child acquire a language before he hears it?! How can he write or read this language before he learns how to write and how to read?

(B) The cultural function: the language performs an exploratory function as it opens new horizons for man to explore the world around him and interact with him through his understanding of the events surrounding him. In addition to the fact that the language has a news function as it conveys to the individual all the developments of life, informs him of all information about the past and the present, and opens new doors for him about the future (P. 37) [11], so we can say, "Language is not an element of culture, but rather it is the basis of cultural activity." (P. 15) [9]. The perfection of language is a condition for the development and advancement of culture.

Through language, he can assimilate all that is new of information and multiple experiences about any part of the globe, through that dangerous technological renaissance that the various media and the computer world enabled him to do with all its developments.

(C) Analytical Functionalism: Language has an analytical function that helps a person formulate his fantasies and perceptions and embody them in audio or written words, as it helps poets and writers to formulate their thoughts and imaginations in an audible or readable form through a poem, story or literary article.

Third: Social Function:

Other sub-functions are branched out from this social function, which are:

(A) The interactive function: language is the strong bond between members of society, as it weaves them into a single thread, and it enables them to interact with each other. "The language bond is stronger than any other social bond" (P. 2) [8].

(B) Organizational function: We use language to control others, to compel them to achieve our interests, to be convinced of our point of view and embrace our ideas, which on the other hand are used by others to control us, achieve their interests, and trace their ideas and opinions (P. 148) [13]. Language, then, is the path of fruitful and orderly cooperation between human beings, and without it, a person is unable to influence or be influenced by people.

(C) The function of social harmony: the language in its reality always feels the individual belongs to a certain gender or a certain nation, and it is that which links him to religion and the state, and it is that which forces him to modify his behavior that is rejected by society, as it is always compatible with the prevailing norms in society, and it is hardly possible. He never gets out of her so that he's not met with mockery or isolation. "This is what has led many psychologists to assert that the extent of an individual's social compatibility is influenced to a large extent by his language, and that his language in turn is affected by the extent of his social compatibility, meaning that the relationship between language and social compatibility is a reciprocal and interactive relationship" (P. 40) [11]. This is because the individual's adaptation to his community gives him a sense of security and reassurance within the community, where he feels adapted and integrated.

\section{Conclusion and Most Important Results}

And yet, we have realized that the most important function of language is the social function. Language is not just a means of expressing ideas and communication between man and his gender only. In many cases it is a response to the innate tendency of man to establish his social existence.

We also realized that the human language has features that 
distinguish it from other non-human languages - if this expression is correct - and for that reason God Almighty distinguished man by language.

The study found the following results:

1. The concept of language for the ancients does not differ from that of modern Linguists except in simple aspects

2. Creatures other than humans cannot acquire any human language in one form or another.

3. The human language is an acquired language, which children acquire from adults, generation after generation, with its ability to continuously develop across generations.

4. The human being has a creative linguistic capacity, so he is able to understand, create and renew.

5. Language creates in a person a broader and broader intellectual capacity, and it also enables a person to develop his thinking and move it from simple and naive ideas to more complex and deep ideas.

\section{References}

[1] Anis, I. (1995), Linguistic Voices, Cairo, the Anglo-Egyptian Library.

[2] Al-Bahnasawi, H. (1993), the Language of the Child in the Light of Modern Linguistic Research Methods, Cairo, AlThaqafa Al-Dinia Library.

[3] Al-Bahnasawi, H. Modern Linguistic Research Methods and its Schools, Fayoum (Cairo), Dar Al-Elm.

[4] Piaget, J. (2001), Language and Thought in a Child, translated by Ahmed Ezzat Rajeh, Second Edition, Cairo, Al-Nahda Almisria Library.

[5] Al-Biyali, A, E. (1989), Studies in the Arabic Language, Cairo, Al-Zahraa Library.
[6] Chomsky, N. (2005), Language and Responsibility, translated / Hussam Al-Bahnasawy, Second Edition, Cairo, Zahraa AlSharq Library.

[7] Al-Jibaly, A. (2003), the Language of the Arabic Child, Cairo, Al-Khanji Library.

[8] Hassan, T. (1990), Research Methods in Language, Cairo, the Anglo-Egyptian Library.

[9] Hassan, T. (2001), the Language between Standardization and Descriptive, Cairo, Aalam Al-kutub.

[10] Hamouda, T, S. (1997), a Study of the Meaning of the Fundamentalists, Cairo.

[11] Shash, S, M, S. (2006), the Psychology of Language, First Edition, Cairo, Zahraa Al Sharq Library.

[12] Shaheen, A. (1986), the Arabic Language of Science and Technology, Second Edition, Cairo, Dar Al- i'tisam.

[13] Abdel Aziz, M, H. (1988), Introduction to Language, Cairo, Dar Al Fikr Al Arabi.

[14] Abdel Aziz, M, H. (1992), Introduction to Linguistics, Cairo, Al-Shabab Library.

[15] Al-Farnawani, R. (1995), Introduction to Contemporary Linguistics, Fayoum (Cairo), Al-Yusr Library.

[16] Corbalis, M. (2006), On the Genesis of Language from the Hand Signal to the Pronunciation of the Mouth, translated by Mahmoud Majed Omar, Kuwait, Aalam Al-maarifa, Issue (325).

[17] Wafi, A, W. (2005), the Genesis of Language at Man and Children, Second Edition, Cairo, Nahdat Misr.

[18] Yusuf, J, S. (1990), Psychology of Language and Mental Illness, Kuwait, Alam Al-maarifa - Issue (145). 